\title{
Grandmothers' perspectives on the changing context of health in India
}

\author{
Solveig A. Cunningham ${ }^{*}$ (D), Susannah D. Gloor ${ }^{2}$ and Shailaja S. Patil ${ }^{3}$
}

\begin{abstract}
Background: The prevalence of obesity and other chronic diseases is increasing in India and around the world. As globalization and social changes are believed to be at the root of these epidemiological changes, these factors must be better understood. This study engaged older adults to gain an important perspective on globalization and health.

Methods: A free-list instrument and a structured survey were developed and used to gather data on changes in diet, activity, and women's roles from ten grandmothers in rural India.

Results: Grandmothers indicated that household chores and food preparation are less labor-intensive and time-consuming due to mechanization and the availability of prepared foods than a generation earlier. Families are more often eating food out, bringing prepared food home, and using ready-made food mixes; adolescents are continuing to eat meals at home, but now snack with friends outside the home more frequently.

Conclusions: Using both a free-list instrument and a structured survey, grandmothers were able to provide insights about the changing context of dietary patterns and family roles arising with globalization that may be contributing to the rise in chronic disease.
\end{abstract}

Keywords: Chronic disease, Globalization, Grandmothers, India, Gender roles, Data collection

\section{Background}

A recent focus of research has been the increase in overweight and obesity in less developed settings, including India [1-4]. This trend may be due to globalizing influences such as urbanization; the mechanization of laborious tasks; new sedentary activities involving televisions and computers; and the availability of cheap, energydense foods [5-8]. In India, this "nutrition transition" is the result of increased availability of meat, milk products, and fats and less consumption of traditional beans, lentils, and other plant-based foods [3]. In addition, the expansion of the global marketplace has introduced new foods altogether into Indian communities. For example, processed foods high in sugars and fats, such as soda, packaged snacks like Oreos, and Cadbury chocolates, are becoming more widespread [9]. This pattern may be due in part to the ways in which transnational food

\footnotetext{
*Correspondence: sargese@emory.edu

${ }^{1}$ Hubert Department of Global Health, Emory University, 1518 Clifton

Road NE, Office 7045, Atlanta, GA 30322, USA

Full list of author information is available at the end of the article
}

companies alter food availability in developing countries in four ways: more processed foods, more fast food outlets, more large supermarkets, and more food advertising and promotion [10]. Furthermore, fried foods like samosas and fried chicken "Manchurian" are traditional foods of North India but are now more available in smaller communities across the country $[9,11]$.

Additionally, sedentary work and pastimes are increasingly common. In a study conducted in the same study area, we found that, for adolescents, active pastimes were the most popular form of recreation, but that the majority of activities children reported doing were sedentary [12]. Sedentary behaviors, such as watching television may be linked with obesity, including in India [7]. The mechanization of certain household tasks and modes of transportation also decreases levels of daily physical activity and is associated with an increase in obesity prevalence [8].

There is limited empirical evidence to provide context for how such changes are actually taking place. One way to obtain a potentially informative perspective on this 
process of change is to engage older adults, who would have witnessed these changes first-hand. Grandmothers especially are stalwarts of the family who spent and continue to spend most of their time within the home. As a result, they may have important insights into how social changes relate to family nutrition and leisure activities. In addition, previous studies have indicated that grandmothers are important forces in shaping the family food environment and promoting children's health [13-18].

To explore the possibilities for garnering a view of sociocultural changes in the context of globalization from older adults, we used two approaches to engage ten grandmothers as part of a larger research program in a remote middle-sized city in India. The focus was on aspects of the home environment relevant to child health from the perceptions of grandmothers about the changes they have witnessed in their families in terms of diet, activity patterns and gender roles in a globalizing community. In this report, we describe preliminary information about the changing environment as it may relate to child health from grandmothers' perspectives, and review the potential feasibility of engaging grandmothers in future research.

This research is based in Bijapur District in the state of Karnataka in Southern India, a socio-economically under-developed area that is undergoing economic, social, and cultural changes associated with globalization. Bijapur City, the main urban center, has increased in population by $43 \%$ since 2001, to an estimated 326,360 [19]. While under-nutrition continues to be a problem, with $42 \%$ of children under the age of 3 years being underweight in Karnataka [20], there is concern that obesity and other chronic disease are emerging.

\section{Methods}

This research was part of a larger study focused on the home environment and risks of unhealthy weight among adolescents. A representative sample of 407 school-going adolescents aged 13-16 years was selected from 3 government and 3 private schools in Bijapur city. A stratified random sample of 201 government school students (102 boys, 99 girls) and 206 private school students (105 boys, 101 girls) was drawn from school rosters. Information from the adolescents and from their mothers was collected about the adolescent, the family, and the home environment in 2012. The cohort was re-visited in 2013 and this study is part of the follow up survey. The BLDE (Bijapur Liberal Development Education Association) University Ethics Committee approved the human subjects protocol for this study; research was carried out in compliance with the Helsinki Declaration.

To recruit participants for this study, we created a list of all sampled households with grandmothers living in them based on information collected in the original survey (122 households of 407). Of these, in 64 households the adolescent was attending private school and in 58 the adolescent was attending public school. We took note of the type of school attended because research from India has indicated socioeconomic differences between families according to the type of school they access. Five households with grandmothers were selected from each list and the ten grandmothers were recruited via telephone after they agreed to participate. Grandmothers were included if they had lived with the present family at least 5 years. All grandmothers who were selected agreed to participate.

As we found no previous studies that engaged grandmothers to study sociocultural changes, an exploratory study was developed using a short structured survey and a free-list instrument (see Additional file 1). The structured questionnaire consisted of 27 close-ended, pre-coded questions and two open-ended questions. It focused on sociocultural characteristics of the grandmother's current household and of the household in which she was the mother of adolescent children decades earlier. Respondents were asked to describe and to compare characteristics of their current and past household, including details of eating, activity practices and daily tasks.

Free-listing is an anthropological method used to learn about an unfamiliar cultural domain and to solidify where concentrated research efforts are warranted [21]. The method involves asking respondents to list as many items as they can in response to a particular concept and probing to encourage participants to mention all aspects that come to their minds. Data collection was conducted orally in respondents' homes in the local language, Kannada, in teams of two in July 2013. Data were gathered from 10 grandmothers, from five grandmothers using structured questionnaires (3 from government and 2 from Private) and from five (3 from private and 2 from government) using the freelisting method. Through both methods, we inquired about topics that are expected, based on the literature, to be pertinent to globalizing changes in diet and lifestyle. The domains covered in freelists were household tasks, roles outside the home, food preparation, eating behaviors, and physical activity. For each domain, the grandmother was asked to compare with the time when their son or daughter were of the same age as the adolescent grandchild included in the research project. The free-list instrument began with the same demographic questions as the survey and included five open-ended questions about gender roles, food preferences and habits, and levels of physical activity in the current and past households. 
Grandmothers' responses on the two instruments were recorded and data were entered in Excel. We listed and tabulated frequencies. Items from the free-lists were tabulated and counted in each domain. Responses to the survey questions were tabulated individually and then cross-tabulated against each other.

\section{Results}

Grandmothers were between 52 and 80 years old; six of them were widowed. Grandmothers had been living in their current living arrangements on average 7 years. Seven were living with their son's family and were thus the paternal grandmothers of the family's children, while three were maternal grandmothers living with their daughter and son-in-law. In this part of India, the cultural norm is for the paternal grandmother to stay with family; when older women have several sons, they may stay with their eldest son, their youngest son, or the son who is managing their ancestral property. A woman may stay with her daughter's family if she is widowed and does not have a son to look after her; it is not uncommon for this maternal grandmother to be the sister of her own son-in-law.

Most households (9/10) belonged to the Hindu religion and the average household had 7 members. The majority of grandmothers $(7 / 10)$ were in the families with average income levels: 10,000-30,000 INR, or 150-450 USD/ month. Among grandmothers, most (9/10) were homemakers and one had work outside the home as an office assistant. Six grandmothers were illiterate and 4 had completed primary education (7th grade). There were no major socio-demographic differences between respondents to the 2 instruments, though grandmothers selected for the freelist instrument were slightly more often grandmothers of private-school adolescents and were also slightly older on average.

\section{Household tasks}

Grandmothers reported that exclusively women were responsible for domestic tasks in their current households and in the household where they had been mothers of adolescent children. In the current household, the mother was always responsible for cooking (i.e. the grandmother's daughter-in-law or daughter). Grandmothers whose grandchildren were in private schools (and generally wealthier) reported that their daughter-inlaw and hired female servants or domestic helpers were responsible currently for house cleaning, laundry, and dishwashing, whereas grandmothers of public school children reported that these tasks were done by her daughter-in-law or granddaughter. Meal preparation, such as cleaning vegetables and grains, was done most frequently by the grandmother herself. In their past households when they had been mothers of adolescents, all grandmothers reported that they, as mothers, had been responsible for all of these tasks themselves. These patterns could suggest that household responsibilities may be shifting somewhat from being solely the responsibility of the mother to being the duties of other women, including hired servants. When asked in the free-list to name duties they themselves had done previously that are not done by mothers now, grandmothers reported (3/5) clothes washing, cooking (1/5), and caring for animals (3/5). Grandmothers (4/5) reported that mothers now have more time for leisure activities compared to in the past since household devices have mechanized the preparation of meals, resulting in less time required for cooking.

\section{Food preparation}

Most grandmothers reported that food preparation has become less laborious now than in the past due to mechanization, availability of gas stoves instead of having to fetch firewood for cooking, and availability of prepared and packaged foods. The majority (4/5) indicated that pre-packaged mixes such as curry powders and masala pastes are more often used to prepare food in their household now than in the past, and that they more often purchase atta (traditional whole grain) flour now rather than grinding grains for flour at home. Almost all $(4 / 5)$ grandmothers reported that they cooked traditional dishes and food items that are not cooked by their daughter-in-law or daughter for their grandchildren. One grandmother said, "earlier there was no grinder, we used to grind [grains] ourselves." All respondents listed "mixer/grinder" as an appliance that is found in households now that was not found when they were mothers of adolescents. Other appliances frequently listed include refrigerator, gas stove, and pressure cooker.

\section{Eating patterns}

Grandmothers (4/5) reported that their grandchildren ate more often at roadside eateries than did their children at the same age, with only one grandmother reporting no difference. Roadside eateries are stands that offer fried fast foods, such as samosas, pani puri (fried crisp stuffed with a spicy mixture), fried noodles, egg omelets, and fried cauliflower ("Manchurian"), many of which are traditional in Northern India, but not in this area. The increase in availability and consumption of these new and previously unknown foods is consistent with research showing that adolescents' consumptions patterns in this region reflect a combination of global, nonlocal, and traditional foods, access, and preferences [9]. Grandmothers also reported that their grandchildren ate snacks outside the home more often than their children 
had at the same age, with two grandmothers reporting not having noticed a difference. Snacking outside the home can include buying bakery products and foods sold at convenience stores, such as chips, cookies, and candy. Pocket money increases adolescents' access to snacking outside the home, and indeed grandmothers observed that pocket money for children is now a phenomenon: In freelists, one grandmother commented, "Earlier, children were not given pocket money, now it is more common practice" and when asked "do you ever give pocket money to your grandchildren to eat outside food," $3 / 5$ said that they do. When asked in the free-list what foods their grandchildren ate now that their children did not eat when they were adolescents, grandmothers listed ready-to-eat foods like instant noodles (Maggi), packaged Cheetos-like snacks (Kurkure), and bakery products like white bread, cake, and pizza. They also listed idli and dosa, which are traditional Indian foods but are more frequently prepared in this area now than in the past due to the ease of preparation that comes with mechanized kitchen tools. One grandmother said, "Previously, we did not eat rice as it was not grown locally, but now rice is eaten more." Another said, "we used to eat jowar (millet) and corn flour rotis; now more wheat and rice is eaten"; this observation may be linked to government-subsidized distribution of these food items.

In the structured survey, all but one grandmother reported that their grandchildren more often ate with friends outside the home than did their children. All grandmothers indicated that the practices of eating outside home and of bringing snacks from outside to the home have increased in comparison to their family in the previous generation. However, all respondents also indicated that the frequency of eating family meals at home has remained same.

\section{Physical activity}

When asked to list activities that their adolescent grandchildren did now that their children had not done when they were the same age, every grandmother reported watching television, and the majority (7/10) reported using the computer or playing mobile games. These reports suggest an increase in adolescents' participation in sedentary activities in the current generation.

\section{Roles outside the home}

In the current household, all grandmothers reported that their son or son-in-law (the father of the adolescents) worked outside the home. This is similar to their experiences when they were mothers of adolescents, when all but one had a husband who worked outside the home. The majority (3/5) of grandmothers also reported that currently their daughter-in-law or daughter worked outside the home. By contrast, only one grandmother reported that she herself had worked outside the home when she was the mother of an adolescent. When asked in the free-list to name tasks that mothers do now that the grandmother did not do when she was raising her children, grandmothers echoed the questionnaire findings that mothers now do "outside work" and "go outside for a job." In addition, they listed (4/5) "going to school" and doing social activities such as going to the movies, parlor (beautician) or meeting with friends wearing modern clothes $(2 / 5)$. These patterns are consistent with increasing participation of women outside the home, both in the formal workforce and in the social sphere.

\section{Discussion}

This study explored a unique perspective of how globalization is changing health by learning from elders who have been observing changes in their communities over the course of their lifetimes. The research was implemented through a structured questionnaire and a free-list exercise conducted with a small sample of grandmothers in a remote developing city in southern India. Grandmothers were asked about norms and habits in their current household and in the household in which they themselves had been mothers of adolescents.

Grandmothers indicated that women continue to be solely responsible for household chores, which most often involve cooking meals, washing clothes and dishes, and cleaning grains, but the distribution of chores may be shifting from being solely the responsibility of mothers to also involving other women, such as hired helpers, daughters, and grandmothers. Grandmothers observed that household chores, particularly grinding and pounding foodstuffs for meals, sewing, washing clothes, gathering fuel, and cooking are changing due to mechanization and the availability of prepared foods, becoming less labor-intensive and time-consuming than a generation before. While mothers continue to be the primary providers of household labor and now participate more often in labor outside the home, they may also enjoy more leisure and educational activities. Understanding time allocation and its implications for family health in poorer settings is an important area of research for future studies.

With respect to children's environments, grandmothers noted that adolescents are eating meals at home as much as they did a generation earlier, but that families are more often eating food out, bringing prepared food home, and using ready-made food mixes than they did previously. Grandmothers also reported that adolescents now snack with friends outside the home more frequently than in the previous generation. Grandmothers' observations about changes in food preparation and eating patterns 
may be relevant to studies examining whether rising obesity levels result from increases in eating "junk" foods, eating outside the home, and expanding in sedentary activities [6-8, 22, 23].

Grandmothers offered insights into some of the changes in eating and activity in their families and in norms occurring over the past generation. They were eager to narrate their experiences as the traditional caretakers of the home and seemed to feel valued due to participation in this research. All grandmothers cooperated fully with both instruments. The structured survey was fast to administer, while the freelisting method was more time-consuming. However, the respondents enjoyed sharing their observations more freely with the latter method. All grandmothers participating in freelisting commented about changing diet patterns, especially more rice consumption and mechanization of food production, about the new trend of giving pocket money to adolescents, and about the expansion of leisure time of mothers today. Free-listing is a method that has promise for engaging older adults in non-Western settings.

This was an exploratory study with a small number of respondents and utilizing two instruments not previously validated. The participants were women co-residing with their grandchildren who were ages $15-18$ years in 2013. They were not selected to be representative of older adults in our study community. As is the case more broadly with studies collecting retrospective data from older adults, the information was reflective of participants' perceptions and narratives, but may not be a reliable source of information about actual changes and events. For example, it may be easier for grandmothers to remember what their grandchildren eat now compared to what their children ate many years ago. Their reports may be shaded by beliefs that they worked harder and did things better than their daughters-in-law and daughters do now, or that, in the past, things were done more "properly" than now; if that is the case, they may overstate changes or the extent of unhealthy behaviors now compared to the past.

Building on this exploratory research, future studies should use adequately-sized population-representative samples of older adults to develop provide insights into the themes on which we were only able to touch broadly here. One useful approach would be to expand and validate the structured instruments developed here to systematically explore differences in perceptions and experiences across genders, age groups, social strata, and rural and urban residence. Using qualitative methods, including focus groups to examine patterns both across families and within families, for example comparing responses of older men and women or of grandmothers and mothers would add further context and may be useful in mapping perceptions to actual experiences.

Studies have shown that grandparents play a role in grandchildren's feeding and activity patterns, especially in Southeast Asian families living with multiple generations $[24,25$.$] A future step for research will be to expand the$ inclusion of grandparents in eliciting information about their roles in deciding grandchildren's diet and activity patterns; asking grandparents about their perceptions of their adolescent grandchildren's weight status would also add knowledge about the family context of weight and weight-related behaviors and about the changing social contexts of health.

\section{Conclusions}

This study demonstrates that older adults can provide valuable information for contextualizing the social and home environments relevant for health. Information from questionnaires and free-lists with older adults can also help guide the development of longitudinal studies that would more directly measure normative and social changes. Such research can enhance understanding of the social context of global behavioral and health changes.

\section{Additional file}

Additional file 1. Survey and free-list instruments used.

\section{Abbreviations}

BLDE: Bijapur Liberal Development Education Association; INR: Indian rupees; USD: United States dollars.

\section{Authors' contributions}

SSP and SAC conceived the study and secured funding for the research; SSP led data collection and contributed to instrument development and to writing the manuscript; SG contributed to instrument development and data management. SAC contributed to instrument development and led writing of the manuscript. All authors read and approved the final manuscript.

\section{Author details}

${ }^{1}$ Hubert Department of Global Health, Emory University, 1518 Clifton Road NE, Office 7045, Atlanta, GA 30322, USA. ${ }^{2}$ Department of Behavioral Sciences and Health Education, Emory University, Atlanta, USA. ${ }^{3}$ Department of Community Medicine, BLDE University Shri B.M.Patil Medical College, Vijayapura, India.

\section{Acknowledgements}

We are thankful to study participants and to Dr. M. C. Yadavannavar for coordinating the data collection and Dr. Veena Algur for translating the instruments into the local language.

\section{Competing interests}

The authors declare that they have no competing interests.

\section{Availability of data and materials}

The instruments are provided as Additional file. The datasets supporting the results of the current study are available from the corresponding author on reasonable request. 


\section{Consent for publication}

Participants were explained the purpose and objectives of the research and their roles and risks and were asked for consent to participate, including the consent for publication of de-identified data.

\section{Ethical approval and consent to participate}

Study participants gave verbal consent to participate in the research.

The research was approved by the Institutional Ethical Committee, BLDE University, Bijapur (586-103).

\section{Funding}

This project was supported by Award Number 3D43HD065249-03S1 from the Eunice Kennedy Shriver National Institute of Child Health \& Human Development and by a grant from Emory University's Global Health Institute. The content is solely the responsibility of the authors and does not necessarily represent the official views of the Eunice Kennedy Shriver National Institute of Child Health \& Human Development. Additional support was provided by BLDE University's Shri B.M. Patil Medical College.

\section{Publisher's Note}

Springer Nature remains neutral with regard to jurisdictional claims in published maps and institutional affiliations.

Received: 26 October 2015 Accepted: 28 June 2017

Published online: 07 July 2017

\section{References}

1. Khadilkar VV, Khadilkar AV, Cole TJ, Chiplonkar SA, Pandit D. Overweight and obesity prevalence and body mass index trends in Indian children. Int J Pediatr Obes. 2011;6(2-2):e216-24. doi:10.3109/17477166.2010.5414 63.

2. Midha T, Nath B, Kumari R, Rao YK, Pandey U. Childhood obesity in India: a meta-analysis. Indian J Pediatr. 2012;79(7):945-8. doi:10.1007/ s12098-011-0587-6.

3. Shetty PS. Nutrition transition in India. Public Health Nutr. 2002;5(1A):17582. doi:10.1079/PHN2001291.

4. Wang Y, Chen HJ, Shaikh S, Mathur P. Is obesity becoming a public health problem in India? Examine the shift from under- to overnutrition problems over time. Obes Rev Offi J Int Assoc Study Obes. 2009;10(4):456-74. doi:10.1111/j.1467-789X.2009.00568.x.

5. Chopra SM, Misra A, Gulati S, Gupta R. Overweight, obesity and related non-communicable diseases in Asian Indian girls and women. Eur J Clin Nutr. 2013. doi:10.1038/ejen.2013.70.

6. Goyal RK, Shah VN, Saboo BD, Phatak SR, Shah NN, Gohel MC, et al. Prevalence of overweight and obesity in Indian adolescent school going children: its relationship with socioeconomic status and associated lifestyle factors. J Assoc Phys India. 2010;58:151-8.

7. Gupta N, Goel K, Shah P, Misra A. Childhood obesity in developing countries: epidemiology, determinants, and prevention. Endocr Rev. 2012:33(1):48-70. doi:10.1210/er.2010-0028.

8. Laxmaiah A, Nagalla B, Vijayaraghavan K, Nair M. Factors affecting prevalence of overweight among 12- to 17-year-old urban adolescents in Hyderabad, India. Obesity (Silver Spring). 2007;15(6):1384-90. doi:10.1038/oby.2007.165.

9. Shaikh NI, Patil SS, Halli S, Ramakrishnan U, Cunningham SA. Going global: indian adolescents' eating patterns. Public Health Nutr. 2016;19(15):2799_ 807. doi:10.1017/S1368980016001087.

10. Hawkes C. Globalization, Food and Nutrition Transitions. Geneva: World Health Organization (Commission on Social Determinants of Health); 2007.

11. Maxfield A, Patil SS, Cunningham SA. Globalization and food prestige among Indian adolescents. Ecol Food Nutr. 2016;55:341-64.

12. Staab EM, Cunningham SA, Thorpe S, Patil SS. A "snapshot" of physical activity and food habits among private school children in India. Childhood. 2016:23(4):537-53.

13. Jiang J, Rosenqvist U, Wang H, Greiner T, Lian G, Sarkadi A. Influence of grandparents on eating behaviors of young children in Chinese threegeneration families. Appetite. 2007:48(3):377-83.

14. Pope SK, Whiteside L, Brooks-Gunn J, Kelleher KJ, Rickert VI, Bradley RH, et al. Low-birth-weight infants born to adolescent mothers: effects of coresidency with grandmother on child development. J Am Med Assoc. 1993:269(11):1396-400.

15. Sear R, Mace R, McGregor IA. Maternal grandmothers improve nutritional status and survival of children in rural Gambia. Proc Biol Sci. 2000;267(1453):1641-7

16. Beise J. The helping and the helpful grandmother: The role of maternal and paternal grandmothers in child mortality in the seventeenth- and eighteenth-century population of french settlers in Quebec, Canada. In: Voland E, Chasiotis A, Schiefenhovel W, editors. Grandmotherhood: the evolutionary significance of the second half of female life. New Brunswick: Rutgers University Press; 2005. p. 215-38.

17. Leonetti DL, Nath DC, Hemam NS, Neill DB. Kinship organization and the impact of grandmothers on reproductive success among matrilineal Khasi and patrilineal Bengali of Northeast India. In: Voland E, Chasiotis A, Schiefenhovel W, editors. Grandmotherhood: the evolutionary significance of the second half of female life. New Brunswick: Rutgers University Press; 2005. p. 194-214

18. Cunningham SA, Elo IT, Herbst K, Hosegood V. Prenatal development in rural South Africa: relationship between birth weight and access to fathers and grandparents. Popul Stud. 2010;64(3):229-46.

19. Bijapur City Census 2011. http://www.census2011.co.in. Accessed 4 Nov 2013.

20. Ghosh S. National family health survey-3 (2007). Indian Pediatr. 2007:44(8):619-20.

21. Bernard HR. Research methods in anthropology: qualitative and quantitative approaches. 4th ed. Oxford: AltaMira Press; 2006.

22. Seth A, Sharma R. Childhood obesity. Indian J Pediatr. 2013;80(4):309-17. doi:10.1007/s12098-012-0931-5.

23. Ranjani H, Pradeepa R, Mehreen TS, Anjana RM, Anand K, Garg R, et al. Determinants, consequences and prevention of childhood overweight and obesity: an Indian context. Indian J Endocrinol Metabol. 2014;18(Suppl 1):S17-25.

24. Li B, AdabEmail P, Cheng KK. The role of grandparents in childhood obesity in China_evidence from a mixed methods study. Int J Behav Nutr Phys Activity. 2015. doi:10.1186/s12966-015-0251-z.

25. Pallan M, Parry J, Adab P. Contextual influences on the development of obesity in children: a case study of UK South Asian communities. Prev Med. 2012;54(3-4):205-11. 